\title{
EXPERIMENTAL MEASUREMENTS FOR SPACE CHARGE RELAXATION IN NOVEL PVC THIN FILM NANO-COMPOSITES
}

\author{
A. Thabet \\ Nano-Technology Research Centre, Faculty of Energy Engineering, South \\ Valley University, Aswan, Egypt
}

(Received November 13, 2011 Accepted December 22, 2011)

\begin{abstract}
Space charge formation in a nano-composite thin film under dc stress at various temperatures was observed using the pulsed electro-acoustic (PEA) method. The Polyvinyl Chloride (PVC) /(Clay, Fumed Silica, and ZnO) nano-composite materials, which are made of Polyvinyl Chloride (PVC) mixed with each one of Clay, Fumed Silica, and $\mathrm{ZnO}$ nano-size filler, have changed their electrical properties than that in pure Polyvinyl Chloride. Therefore, the materiasls are expected to be used with smaller thickness as an insulator in the same dc applications. However, it is necessary to study the space charge characteristics, therefore, we tried to investigate the space charge formation in thin film of Polyvinyl Chloride (PVC) / (Clay, Fumed Silica, and $\mathrm{ZnO}$ ) nano-composite materials under dc electric field at various concentrations of nanofillers and $d c$ voltages using PEA system. From the experimental results, it was found that the space charge formation was strongly affected by the Clay, Fumed Silica, and $\mathrm{ZnO}$ contents in their nanocomposites.
\end{abstract}

KEYWORDS: Space charge, Nano-composite, PEA system, Polymers, Insulation, Nanoparticles

\section{INTRODUCTION}

Polyvinyl Chloride PVC is the most widely used of any of the thermoplasts, polymerized vinyl chloride, and which is produced from ethylene and anhydrous hydrochloric acid. PVC is stronger and more rigid than other general purpose thermoplastic materials like ac and dc cable insulations, etc. It has a high tensile strength and modulus of elasticity. Additives are used to further specific end uses, such as thermal stabilizers, lubricity, impact modifiers, and pigmentation. In recent years there has been a constant increase of interest in possible applications of nanocomposite materials in the field of polymeric insulation technology. The adoption of inorganic additives (fillers) in a polymeric matrix, in order to create a composite material is a common technique. By reducing the filler's particle dimensions to the nanometric scale, it is possible to dramatically increase the number of interactions between the organic (matrix) and the inorganic (filler) phase; although the link between interfacesize effect and macroscopic performances is not plainly understood, this fact can originate smart properties in the material. In particular it has been demonstrated that the employment of organically modified layered silicate (clays such as montmorillonite, etc) as filler may increase the thermal resistance, the mechanical strength, the flame retardancy and the gas impermeability [1-5], by using a filler rate equal to 5\% -10 typical of "conventional" nanofillers. With rapid development of the 
world's major cities, the electric energy consumption is increasing annually. Due to this demand, direct current transmission technology which can reduce the costs and energy losses has been a hot topic in the electrical engineering domain. The high voltage DC plastic insulated cable has gradually replaced oil-paper insulated DC cables for the advantage of relatively small volume, great transmission capacity and no maintenance. Polyvinyl Chloride PVC is widely used as an insulating material for power cables due to its excellent mechanical, thermal and dielectric properties. However, the nonhomogenous distribution of space charge in the cable insulation may distort the distribution of electric field which will reduce the dielectric strength and accelerate the deterioration of the insulation. Especially when the voltage is switched off or the polarity is reversed, this phenomenon becomes more apparent [6-11]. Up to now there are many papers reporting dielectric properties of polymeric nanocomposite, of which space charge distribution is investigated in details, for example, space charge at various electric stresses, its inception field and etc. Since most of engineering dielectric concerning to various electrode materials, it is inevitable to considering whether space charge distribution in polymer nanocomposite is sensitive to electrode materials. It stimulates us to fall in step with space charge characterization in the convention dielectric materials. With the pulsed electro-acoustic method (PEA), space charge in a nanocomposite was investigated with different metal electrode pairs, as well as space charge. However, the suppression mechanism of space charge accumulation by adding nano-fillers to polymers under high electric field at high temperature has not been clear yet. Therefore, it has been proposed a charge trapping effect of induced potential well at interface between polymer and nano-fillers based on difference between their permittivities [12-16]. However, there are few papers concerning the effect of types of nanofilers on space charge distribution in polymeric nanocomposite. With a continual progress in polymer nanocomposites, this research depicts the effects of types and concentration of nanoparticles in new nanocomposite industrial polymer material. All experimental results have been investigated and discussed to detect all effects of nanofillers on Space Charge Dynamics in PVC/(Clay, Fumed Silica, and $\mathrm{ZnO}$ ) nanocomposite materials under DC Stress.

\section{EXPERIMENTAL SETUP}

Acoustic wave propagation in the thick samples is significantly attenuated and dispersed due to the loss and dispersive properties of the polymer and principle of space charge measurement using the PEA technique. The specifications of each module in PEA system is being as follows: The oscilloscope (LECROY, LC334AM, $500 \mathrm{MHz}$ ), impulse generator (TECHMP, $10 \mathrm{nsec}$ ), VHF fixed attenuator (30W, 50 $\square$, $40 \mathrm{~dB}$ ) and stabilised voltage supply (Type L30). Measurements are performed in silicon oil to avoid partial discharges, and to keep the temperature constant. The applied voltage was monitored simultaneously by using a resistance voltage divider. In order to observe the effect of pre-stressing on impulse breakdown, it existed that an impulse generator, and a coupling capacitor $(2000 \mathrm{pF})$. Figure (1) shows Life photo and Schematic diagram of the PEA system which used in measuring. 


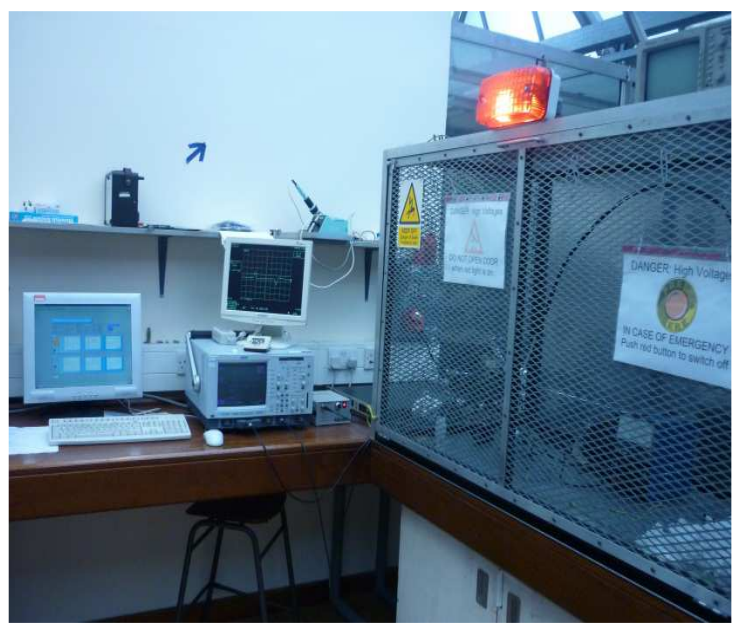

Fig. 1.a. Life photo for experimental PEA system testing equipment's

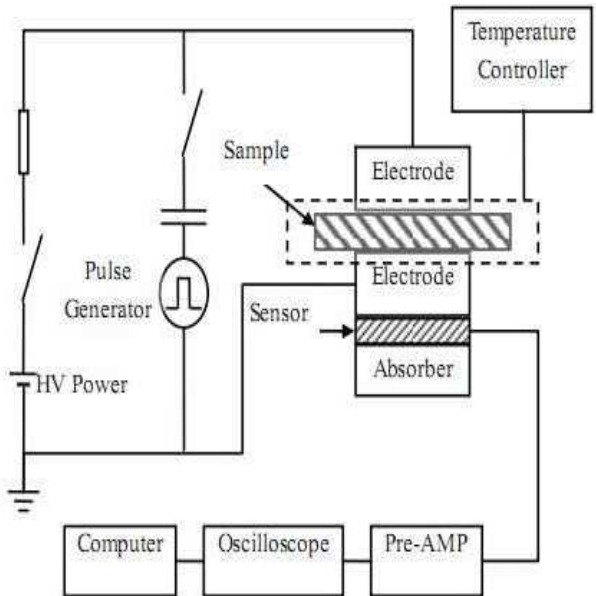

Fig. 1.b. Schematic diagram of PEA system equipment's

Fig. 1. PEA system testing equipment's

\section{MATERIAL PREPARATION AND CHARACTERIZATION}

The industrial materials studied here is Polyvinyl Chloride, has been formulated utilizing nano particulates of clay. The base of all these polymer materials is a commercially available material already in use in the manufacturing of high-voltage (HV) industrial products and their properties detailed in table (1). Additives of clay, $\mathrm{ZnO}$ and fumed silica nanoparticles to the base industrial polymers has been fabricated by using mixing, ultrasonic, and heating processes in Nano-technology Research Centre, Aswan - Egypt as shown in Figure (2).

\section{Table (1) Dielectric Properties of Pure and Nano-composite Materials}

\begin{tabular}{lcc}
\hline \hline \multicolumn{1}{c}{ Materials } & $\begin{array}{c}\text { Dielectric } \\
\text { Constant at 1kHz }\end{array}$ & $\begin{array}{c}\text { Resistivity } \\
(\mathbf{\Omega . m})\end{array}$ \\
\hline PURE PVC & 3.3 & $10^{13}$ \\
PVC + 5\%wt Clay & 3.04 & $10^{13}-10^{14}$ \\
PVC + 10\%wt Clay & 2.85 & $10^{14}-10^{15}$ \\
PVC + 5\%wt Fumed Silica & 3.29 & $10^{13}-10^{12}$ \\
PVC + 10\%wt Fumed Silica & 3.29 & $10^{12}-10^{11}$ \\
PVC + 10\%wt ZnO & 2.5 & $10^{15}-10^{16}$ \\
\hline \hline
\end{tabular}

Additives of clay, zinc oxide, and fumed silica nanoparticles to the base industrial polymers (Polyvinyl Chloride) has been fabricated by using mixing, ultrasonic, and heating processes in Nano-technology Research Centre, Aswan - Egypt. Preparations of studied Polyvinyl Chloride nanocomposites have been used SOL-GEL method. The sol-gel processing of the nanoparticles inside the polymer dissolved in 
non-aqueous or aqueous solution is the ideal procedure for the formation of interpenetrating networks between inorganic and organic moieties at the milder temperature in improving good compatibility and building strong interfacial interaction between two phases. This process has been used successfully to prepare nanocomposites with nanoparticles in a range of polymer matrices. Several strategies for the sol-gel process are applied for formation of the hybrid materials. One method involves the polymerization of organic functional groups from a preformed sol-gel network. The sol- gel process is a rich chemistry which has been reviewed elsewhere on the processing of materials from glass to polymers. The organic-inorganic hybrid nanocomposites comprising of polymer, and nanoparticles were synthesized through sol-gel technique at ambient temperature. The inorganic phase was generated in situ by hydrolysis-condensation of tetraethoxysilane (TEOS) in different concentrations, under acid catalysis, in presence of the organic phase, polymer, dissolved in formic acid [17]. Finally, It can be measured all dielectric properties for pure and nanocomposite industrial materials by using HIOKI 3522-50 LCR Hi-tester device and have been detected as shown in table (1).

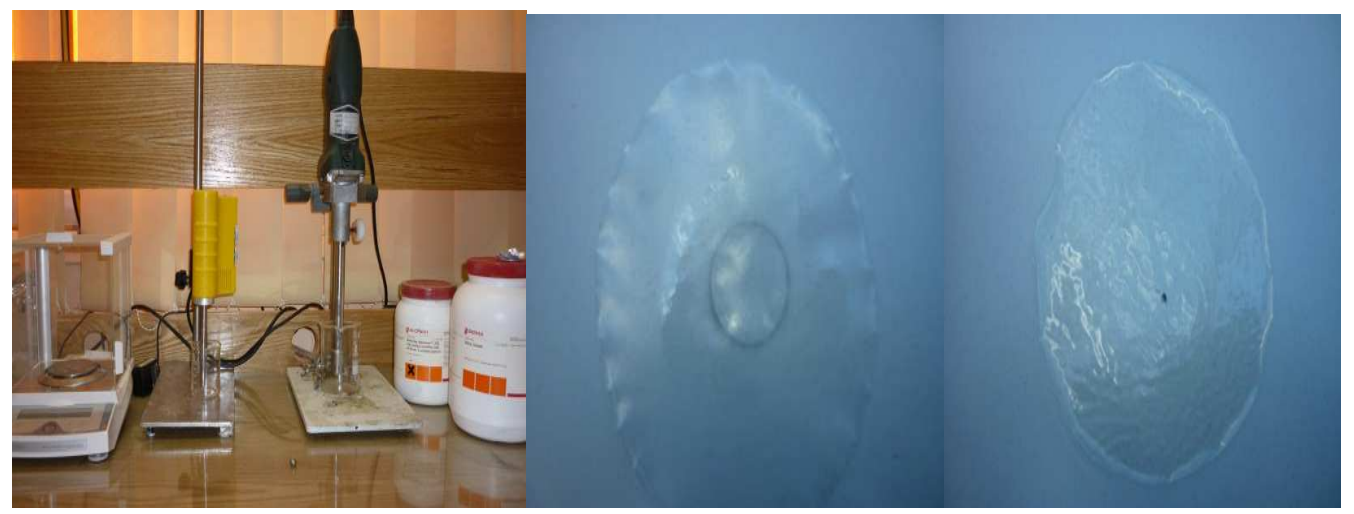

Fig. 2.a. Life photo for preparation Fig. 2.b. Photo for DC breakdown for equipment's nanocomposite of Polyvinyl Chloride PVC with $10 \%$ Fumed Silica under DC electric field

Fig.2. Experimental preparation equipment's and tested samples

\subsection{Properties of Clay Nanofillers}

- Nanoclay: It is nanomer $1.30 \mathrm{E}$, clay surface modified with 25-30wt. \% octadecylamine. The main constituent of nanofiller clays significant quantities of other nanoclays can often be present. Spherical particle shape is the most important characteristic of nanoclay for polymer applications. The platy nature means that clay fillers have a greater effect on properties such as viscosity, stiffness and strength, using clay as nanofiller gives high levels of flame retardancy to the produced composite, and it's selected in this study. Cost less of clay catalyst to be the best filler among nano-fillers industrial materials.

- Fumed Silica $\left(\mathrm{SiO}_{2}\right)$ is a fluffy white powder with an extremely low density, marketed under trade names such as Aerosil and Cab-o-sil. With both 
hydrophobic and hydrophillic grades available, it is widely used as a rheology modifier, imparting highly thixotropic properties at relatively low percentages. It can also provide increased track, better stability in suspensions and prevents "sagging" and settling of solids in a liquid system. For this reason it is particularly suitable for coatings, inks, adhesives, resins, sealants, and greases. Fumed silica, or fumed silicon dioxide, is produced by the vapor-phase hydrolysis of silicon tetrachloride in an $\mathrm{H} 2 / \mathrm{O} 2$ flame. Hydrophilic fumed silica bearing hydroxyl groups on its surface is produced by this process. Fumed silica powders used in paints and coatings, silicone rubber and silicone sealants, adhesives, cable compounds and gels, printing inks and toner, and plant protection.

- Zinc oxide $(\mathrm{ZnO})$ : is a popular cross-linker for rubber and for various resins, it is also used as an UV stabilizer, and it has a relatively high refractive index which makes it an efficient white pigment. Zinc oxide is an inorganic compound with the formula $\mathrm{ZnO}$. It has high refractive index, high thermal conductivity, nontoxic, and compatible with skin, making it a suitable additive for textiles and surfaces that come in contact with humans. Zinc Oxide is also used as a catalyst for methanol synthesis. The increase in surface area of Nano scale zinc oxide compared to larger powders has the potential to improve the efficiency of these processes.

\subsection{Properties of Industrial Polymers}

- Polyvinyl Chloride (PVC) is the most widely used of any of the thermoplasts, polymerized vinyl chloride, and which is produced from ethylene and anhydrous hydrochloric acid. PVC is stronger and more rigid than other general purpose thermoplastic materials. It has a high tensile strength and modulus of elasticity. Additives are used to further specific end uses, such as thermal stabilizers, lubricity, impact modifiers, and pigmentation. There are two basic forms of PVC rigid and plasticized. Rigid PVC, as its name suggests, is an unmodified polymer and exhibits high rigidity. Unmodified PVC is stronger and stiffer than PE and PP. Plasticized PVC is modified by the addition of a low molecular weight species to flexibilize the polymer. Plasticized PVC can be formulated to give products with rubbery behaviour. It is modified by the addition of styrene butadiene rubber which improves notch toughness and impact strength. PVC's are basically tough and strong, resist water and abrasion, and are excellent electrical insulators.

\section{RESULTS AND DISCUSSION}

Fabricated and testing nanocomposite industrial materials have been done by using all experimental setup and equipment's in Nano-Technology Research Center. But, all PEA system testing results have been performed in University of Leicester, Electrical and Electronic Engineering group and have been discussed as shown below. An initial measurement was carried out using two semiconductor electrodes. Electrical breakdown measurements were carried out by placing specimens in a mineral oil vessel, kept at $20{ }^{\circ} \mathrm{C}$, and using cylindrical stainless steel electrodes with diameter 50 
$\mathrm{mm}$. Breakdown voltage up to $7.5 \mathrm{kV}$. Tests were realized applying an increasing $\mathrm{dc}$ voltage. The following figures show space charge distribution at various dc voltage stressed and at variant period times. It can be seen that the positive and negative space charge peaks related to the cathode and anode electrodes that found subsequently using variant applied voltages and times. It has been noticed that all our measurements were therefore obtained using silicone oil to maintain an acoustic contact.

\subsection{Characterization of Pure Polyvinyl Chloride PVC Industrial Polymers}

Figure 3 shows space charge profiles relevant to Polyvinyl Chloride (PVC) pure, up to DC electric field of $70 \mathrm{kV} / \mathrm{mm}$. A considerable amount of charge mainly positive can be seen in the specimen of PVC. Thus, Figure 3 contrasts on the space charge distribution with rising voltage. The measurements imply the injection of impulse high voltages on the charge density of Pure PVC dielectric materials; the cathode is at the left and the anode is at the right that the charge density increases up to $\pm 17 \mathrm{C} / \mathrm{m}^{3}$ with increasing impulse voltages up to $5 \mathrm{kV}$ and hetero-charge accumulated near the cathode.

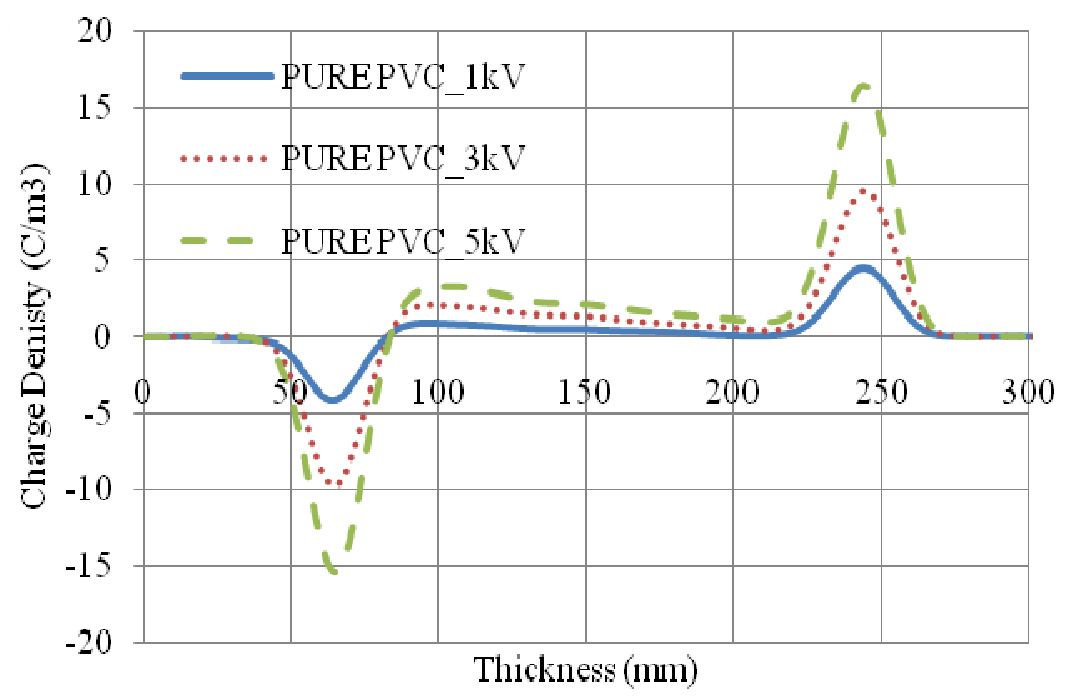

Fig. 3. Space charge profiles for Pure Polyvinyl Chloride PVC under DC electric field

Figure 4 contrasts on the space charge distribution, and its decay happened in remaining voltage, observed in the samples after half hour space charge electrodes. Thus, Figure 4 contrasts on the effects of the space charge distribution, at remaining $5 \mathrm{kV}$ voltage on pure Polyvinyl Chloride PVC materials. Charge density increases from $\pm 15 \mathrm{C} / \mathrm{m}^{3}$ up to $\pm 20 \mathrm{C} / \mathrm{m}^{3}$ with remaining impulse voltages at $5 \mathrm{kV}$ only at the Anode and the hetero-charge accumulated near the cathode is not increased. The data from the first measurement, estimated to correspond to a decay time of $6 \mathrm{sec}$, must therefore be treated with some caution. The measurements therefore imply the injection of negative charge from the cathode, which remains trapped close to the injecting electrode when the duration is $1 / 2 \mathrm{hr}$. 


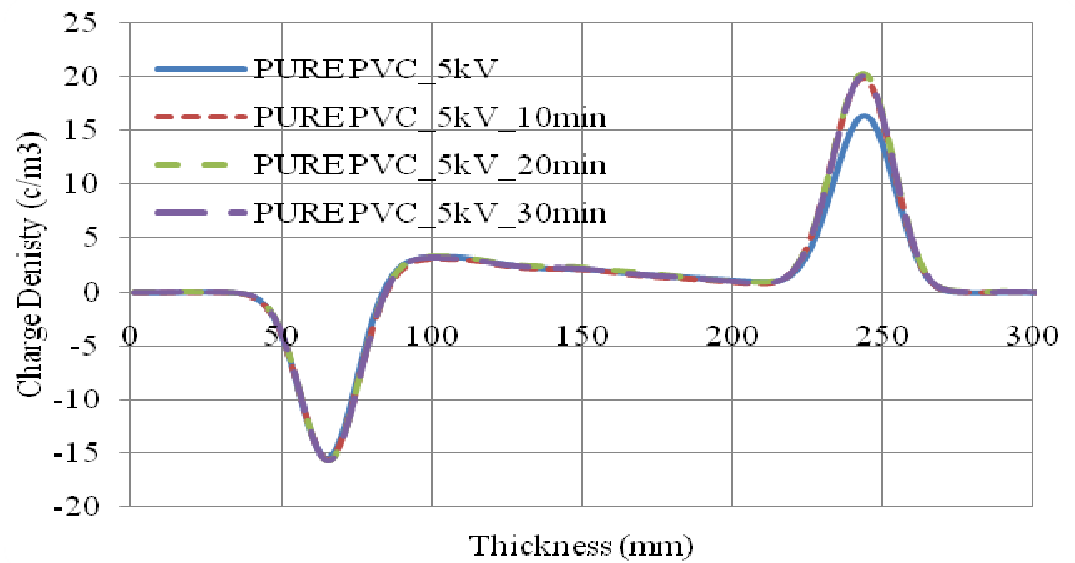

Fig. 4. Space charge profiles for Pure Polyvinyl Chloride PVC under DC electric field

\subsection{Effect of Clay Nanoparticles on Polyvinyl Chloride PVC Industrial Polymers}

Figure 5 shows space charge profiles relevant to Polyvinyl Chloride (PVC) with 5\% clay nanoparticles, up to DC electric field of $70 \mathrm{kV} / \mathrm{mm}$. A considerable amount of charge mainly positive can be seen in the nanocomposite specimen, and so, Figure 5 contrasts on the space charge distribution with rising voltage up to $5 \mathrm{kV}$. The measurements imply the injection of impulse high voltages on the charge density of Polyvinyl Chloride PVC with 5\%Clay nanocomposite materials; charging density at the anode is more than charging density at the cathode with increasing impulse applied voltages up to $5 \mathrm{kV}$ and there is hetero-charge accumulated near the cathode. Figure 6 contrasts the space charge distribution, and its decay which is happened in remaining $5 \mathrm{kV}$ dc voltage, and is observed in the samples after half hour between space charge electrodes. Thus, Figure 6 contrasts on the effects of the space charge distribution, at remaining $5 \mathrm{kV}$ voltage on Polyvinyl Chloride PVC with $5 \%$ clay nanocomposite material. There is no changing in Charge density with remaining impulse voltages but there is a very small reduction at the Anode.

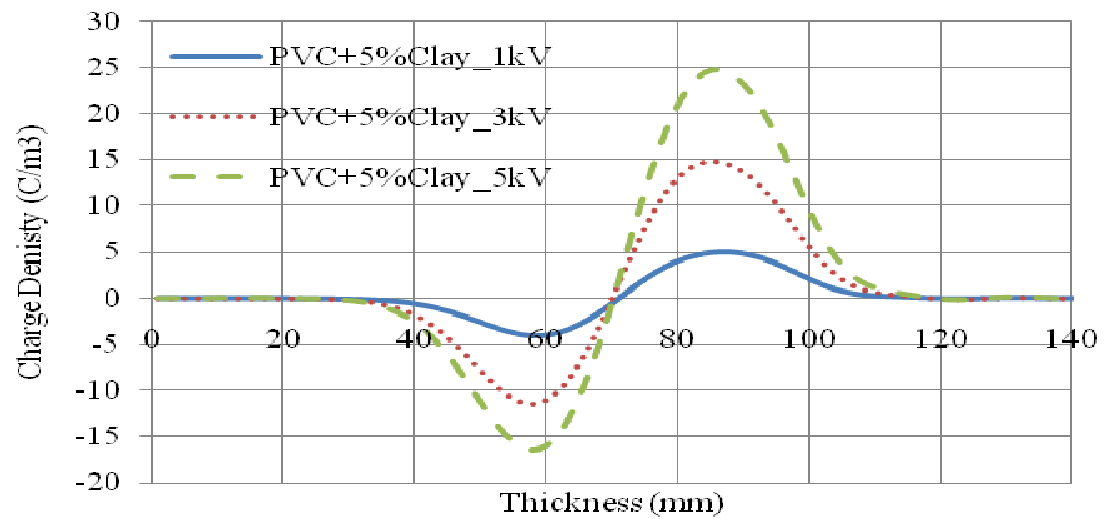

Fig. 5. Space charge profiles for nanocomposite of Polyvinyl Chloride PVC with $5 \%$ Clay under DC electric field 


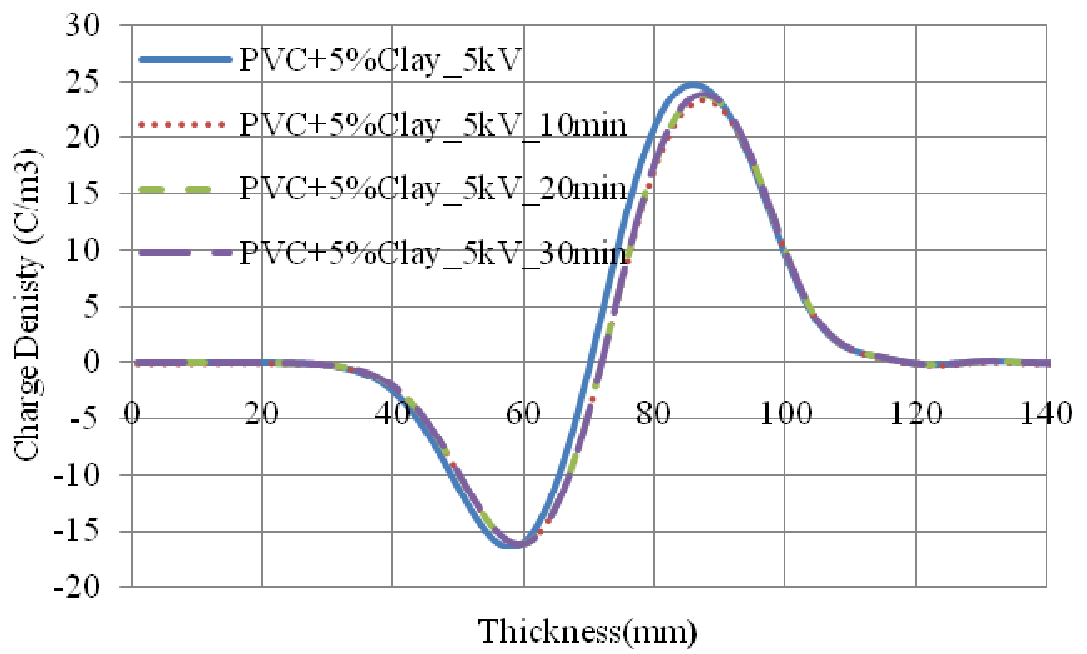

Fig. 6. Space charge profiles for nanocomposite of Polyvinyl Chloride PVC with $5 \%$ Clay under DC electric field

Figure 7 contrasts the space charge distribution with rising voltage up to $5 \mathrm{kV}$. The measurements imply the injection of impulse high voltages on the charge density of Polyvinyl Chloride PVC with 10\% clay nanocomposite materials; charge density at the anode and cathode is increased in nanocomposite PVC with $10 \%$ clay and there are hetero-charge accumulated charges between the anode and cathode electrodes. Figure 8 contrasts the space charge distribution, and its decay happened in remaining voltage, observed in the samples after half hour between space charge electrodes. Thus, Figure 8 contrasts on the effects of the space charge distribution, at remaining $5 \mathrm{kV}$ voltage on Polyvinyl Chloride PVC with 10\%clay nanocomposite material. There is high reduction in charge density at anode and cathode with remaining impulse voltages at $5 \mathrm{kV}$.

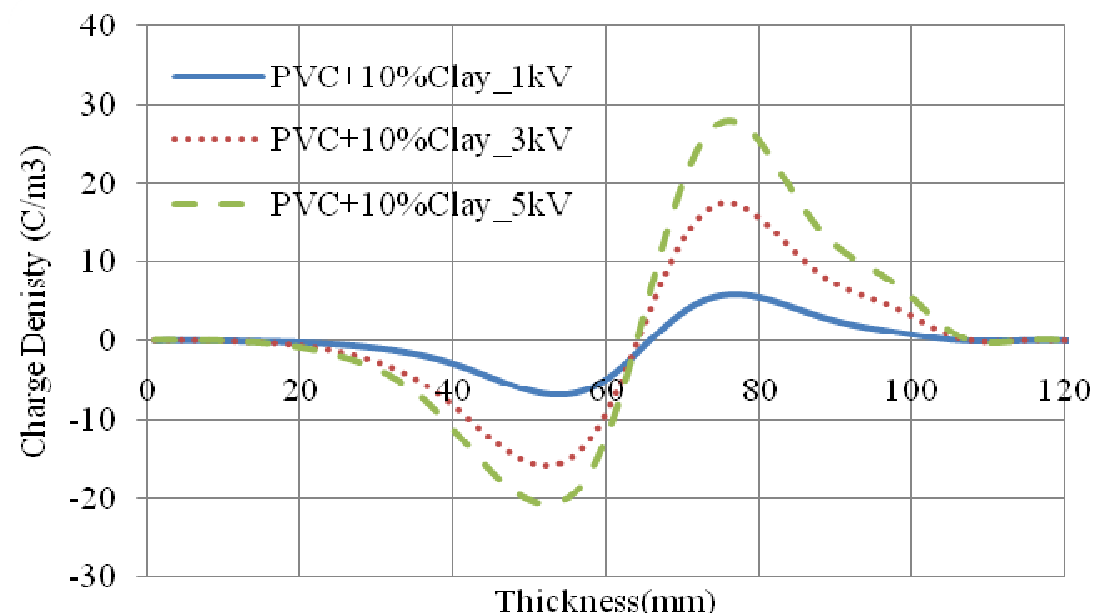

Fig. 7. Space charge profiles for nanocomposite of Polyvinyl Chloride PVC with $10 \%$ Clay under DC electric field 


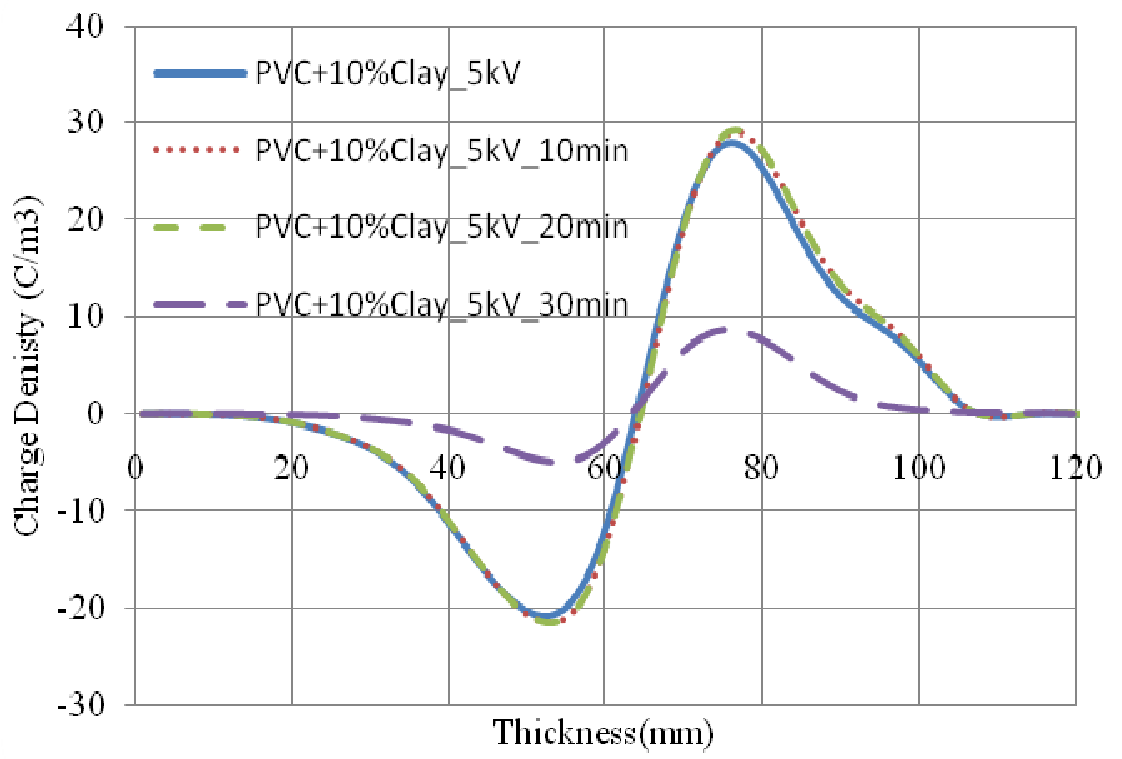

Fig. 8. Space charge profiles for nanocomposite of Polyvinyl Chloride PVC with $10 \%$ Clay under DC electric field

The effect of raising concentration of nanofiller is pointed out in Figures 5- 8 where space charge profiles under applied dc impulse voltages are reported for different weight concentrations of modified nanofillers concentration. i.e. increasing percentages of clay nanoparticles from $0 \%$ clay in pure PVC, up to 5\%clay, and $10 \%$ clay increases charge density about $20 \%$. As can be seen, a progressive of bulk space charge at the electrode field level is observed as the nanofillers concentration increases. Again as referred to charge in the bulk and not the electrode peaks. With aging under $5 \mathrm{kV}$, charge density at the anode and cathode is decreased lightly in PVC with 5\%clay but there is more reduction in charge density that happened in nanocomposite PVC with 10\% clay and there are hetero-charge accumulated charges between the anode and cathode electrodes. A summary of space charge measurements is provided by the threshold characteristics of Figures 5-8, relevant to pure, 5\%clay, and $10 \%$ clay respectively.

\subsection{Effect of Fumed Silica Nanoparticles on Polyvinyl Chloride PVC Industrial Polymers}

Figure 9 shows space charge profiles relevant to Polyvinyl Chloride (PVC) with $5 \%$ fumed silica nanoparticles, in a DC electric field of $70 \mathrm{kV} / \mathrm{mm}$. A considerable amount of charge mainly positive can be seen in the nanocomposite specimen, and so, Figure 9 contrasts on the space charge distribution with rising voltage up to $5 \mathrm{kV}$. The measurements imply the injection of impulse high voltages on the charge density of Polyvinyl Chloride PVC with 5\%fumed silica nanocomposite materials; charging density at the anode is more than charging density at the cathode with increasing impulse applied voltages up to $5 \mathrm{kV}$ and there is hetero-charge accumulated near the anode. 


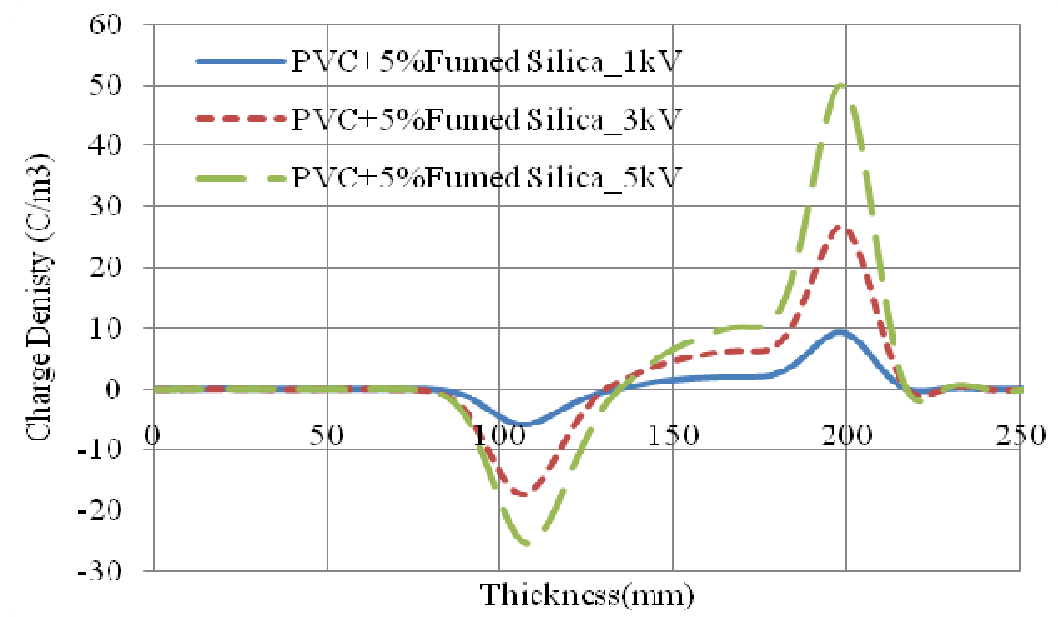

Fig. 9. Space charge profiles for nanocomposite of Polyvinyl Chloride PVC with $5 \%$ Fumed Silica under DC electric field

Figure 10 contrasts the space charge distribution, and its decay which is happened in remaining $5 \mathrm{kV}$ dc voltage, and is observed in the samples after half hour between space charge electrodes. So that, Figure 10 contrasts on the effects of the space charge distribution, at remaining $5 \mathrm{kV}$ voltage on Polyvinyl Chloride PVC with $5 \%$ fumed silica nanocomposite material. There is no changing in Charge density with remaining impulse voltages but there is a very small rising at the Anode. Figure 11 contrasts the space charge distribution with rising voltage up to $5 \mathrm{kV}$. The measurements imply the injection of impulse high voltages on the charge density of Polyvinyl Chloride PVC with 10\%fumed silica nanocomposite materials; charge density at the anode and cathode is decreased to lowest values in nanocomposite PVC with $10 \%$ clay and there are no hetero-charge accumulated charges between the anode or cathode electrodes.

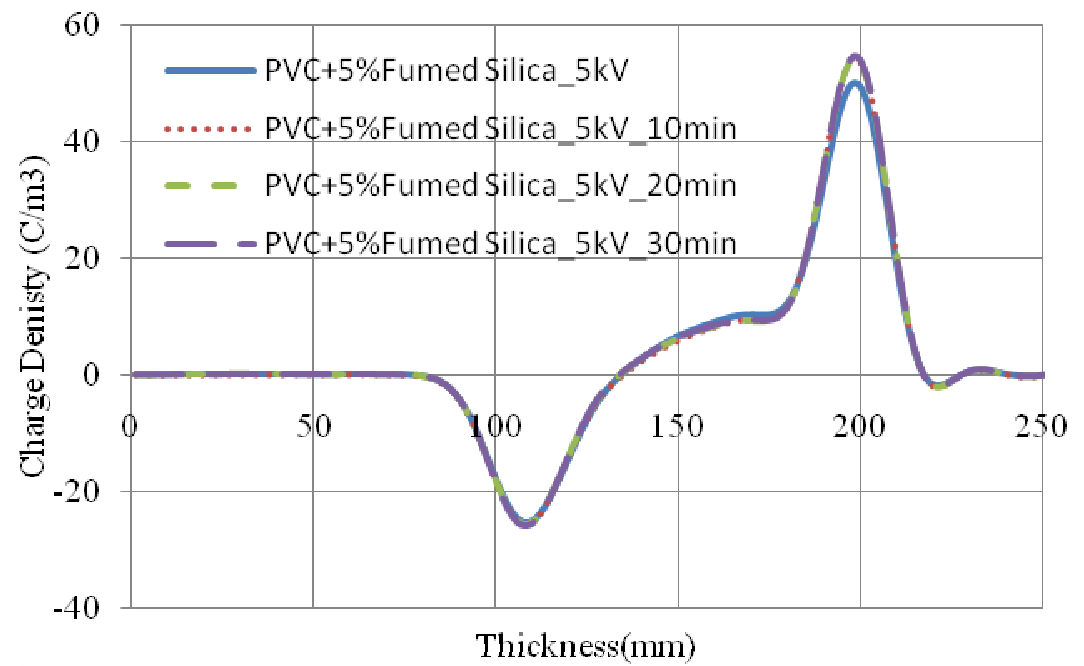

Fig. 10. Space charge profiles for nanocomposite of Polyvinyl Chloride PVC with $5 \%$ Fumed Silica under DC electric field 


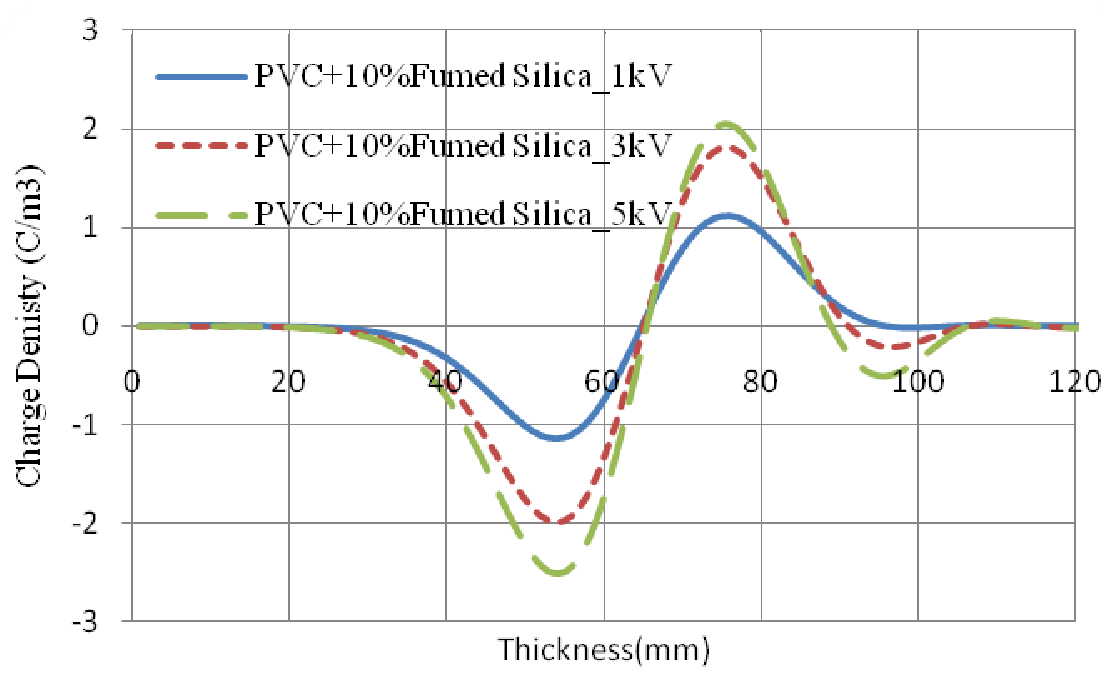

Fig. 11. Space charge profiles for nanocomposite of Polyvinyl Chloride PVC with 10\%Fumed Silica under DC electric field

Figure 12contrasts on the space charge distribution, and its decay happened in remaining voltage, observed in the samples after half hour between space charge electrodes. Thus, Figure 12 contrasts on the effects of the space charge distribution, at remaining $5 \mathrm{kV}$ voltage on Polyvinyl Chloride PVC with $10 \%$ fumed silica nanocomposite material. There is small changes in charge density at anode and cathode with remaining impulse voltages at $5 \mathrm{kV}$.

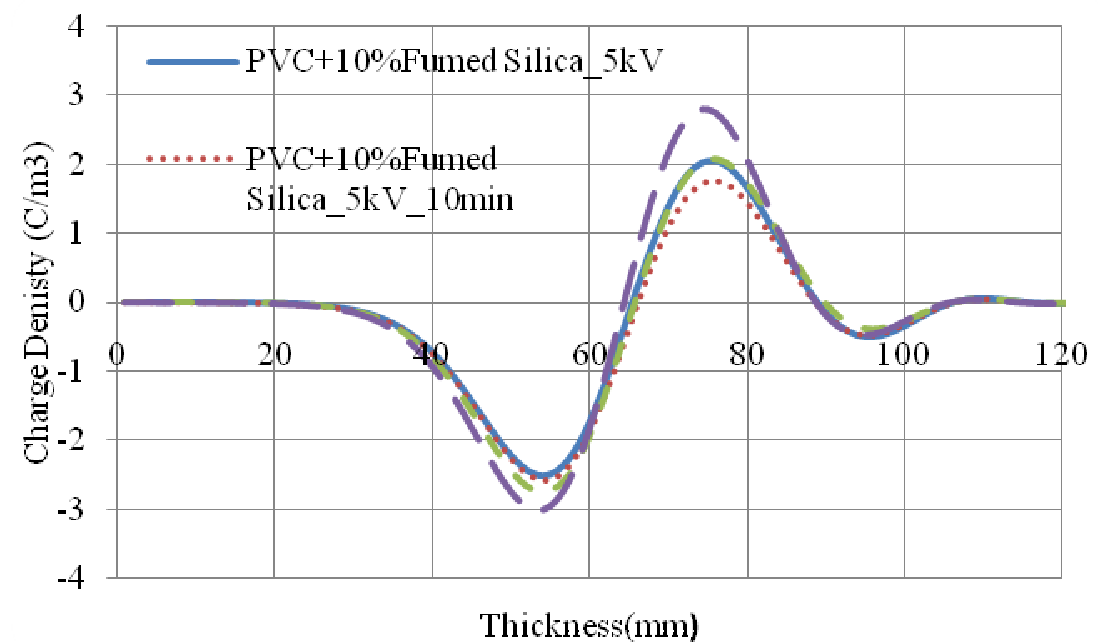

Fig. 12. Space charge profiles for nanocomposite of Polyvinyl Chloride PVC with 10\%Fumed Silica under DC electric field

Comparing with all results for depicting the effect of raising concentration of fumed silica nanofillers is pointed out in Figures 9- 12 where space charge profiles under applied dc impulse voltages are reported for different weight concentrations of 
modified nanofillers concentration. i.e. increasing percentages of fumed silica nanoparticles from $0 \%$ fumed silica, up to $5 \%$ fumed silica increases charge density $200 \%$. As can be seen, a progressive of bulk space charge at the electrode field level is observed as the nanofillers concentration increases to 5\%fumed silica but there is high reduction in charge density, reaches to $80 \%$, if fumed silica percentage increased from $5 \%$ up to $10 \%$. Again as referred to charge in the bulk and not the electrode peaks. With aging under $5 \mathrm{kV}$, charge density at the anode and cathode is decreased lightly in PVC with 5\%fumed silica but there is noticed high reduction in charge density that happened in nanocomposite PVC with 10\% fumed silica and there are no hetero-charge accumulated charges between the anode and cathode electrodes. A summary of space charge measurements is provided by the threshold characteristics of Figures 5-8, relevant to pure, $5 \%$ fumed silica, and $10 \%$ fumed silica respectively.

\subsection{Effect of Zinc Oxide Nanoparticles on Polyvinyl Chloride PVC Industrial Polymers}

Figure 13 shows space charge profiles relevant to Polyvinyl Chloride (PVC) with $5 \% \mathrm{ZnO}$ nanoparticles, in a DC electric field of $70 \mathrm{kV} / \mathrm{mm}$. A considerable amount of charge mainly positive can be seen in the nanocomposite specimen, and so, Figure 13 contrasts on the space charge distribution with rising voltage up to $5 \mathrm{kV}$. The measurements imply the injection of impulse high voltages on the charge density of Polyvinyl Chloride PVC with $5 \% \mathrm{ZnO}$ nanocomposite materials; charging density at the anode is more than charging density at the cathode with increasing impulse applied voltages up to $5 \mathrm{kV}$ and there is hetero-charge accumulated near the anode. Figure 14 contrasts the space charge distribution, and its decay which is happened in remaining $5 \mathrm{Kv}$ dc voltage, and is observed in the samples after half hour between space charge electrodes. So that, Figure 14 contrasts on the effects of the space charge distribution, at remaining $5 \mathrm{kV}$ voltage on Polyvinyl Chloride PVC with $5 \% \mathrm{ZnO}$ nanocomposite material. There is no changing in Charge density with remaining impulse voltages but there is a very small rising at the Anode up to $250 \%$ of pure PVC.

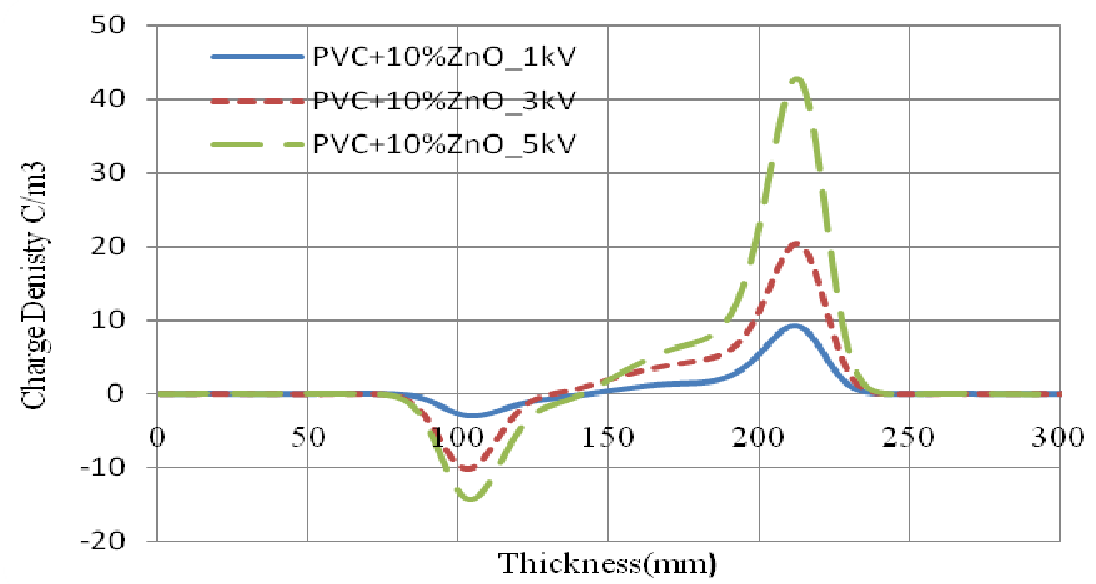

Fig. 13. Space charge profiles for nanocomposite of Polyvinyl Chloride PVC with $10 \% \mathrm{ZnO}$ under DC electric field 


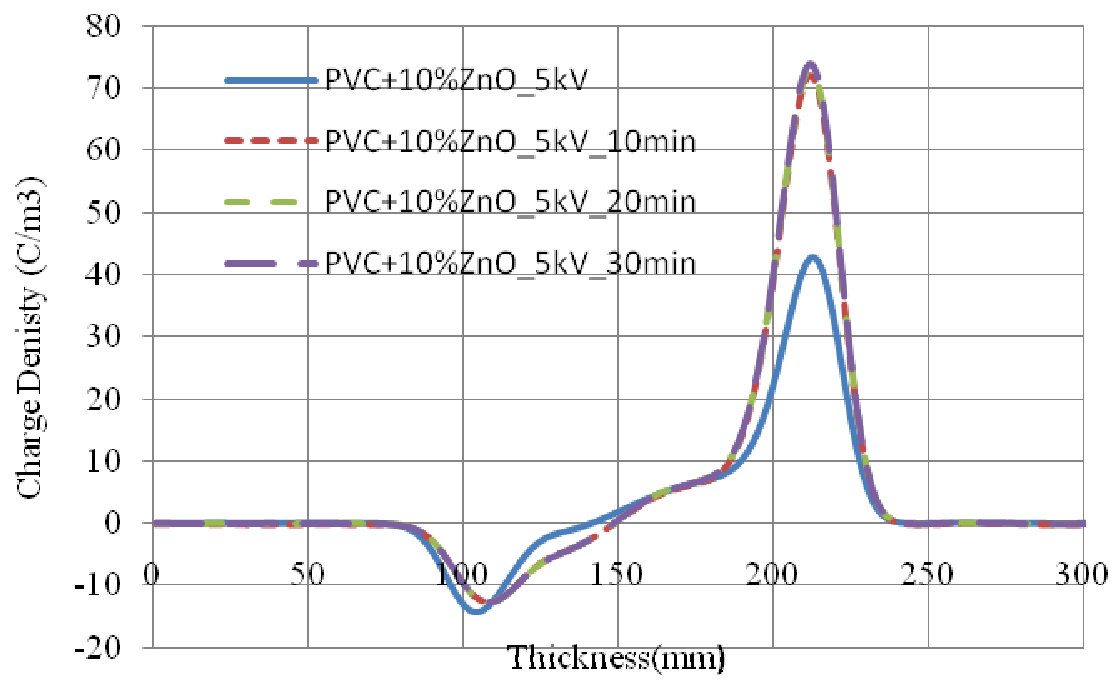

Fig. 14. Space charge profiles for nanocomposite of Polyvinyl Chloride PVC with $10 \% \mathrm{ZnO}$ under DC electric field

Comparing with all results for depicting the effect of raising concentration of $\mathrm{ZnO}$ nanofillers is pointed out in Figures $(13,14)$ where space charge profiles under applied dc impulse voltages are reported for increasing $\mathrm{ZnO}$ concentrations of modified nanofillers concentration. i.e. increasing percentages of $\mathrm{ZnO}$ nanoparticles from $0 \% \mathrm{ZnO}$, up to $10 \% \mathrm{ZnO}$ increases charge density $250 \%$ from that happened in pur PVC. As can be seen, a progressive of bulk space charge at the electrode field level is observed as the nanofillers concentration increases to $10 \% \mathrm{ZnO}$. Again as referred to charge in the bulk and not the electrode peaks, with aging under $5 \mathrm{kV}$, charge density at the anode and cathode is increased in PVC with $10 \% \mathrm{ZnO}$ and there are hetero-charge accumulated charges between the anode and cathode electrodes. A summary of space charge measurements is provided by the threshold characteristics of Figures $(13,14)$, relevant to pure $\mathrm{PVC}$, and $10 \% \mathrm{ZnO}$ nanocomposite respectively. It is noticed that, charge density increases with raising $\mathrm{ZnO}$ nanofillers percentage to $10 \% \mathrm{ZnO}$ in PVC. At aging under $5 \mathrm{kV}$, charge density has been increased at the anode and cathode more than that happened in pure PVC and other studied nanocomposites.

\section{CONCLUSIONS}

- Adding clay nanoparticles increases charge density $20 \%$ and so with aging under $5 \mathrm{kV}$, charge density at the anode and cathode is decreased lightly in PVC with $5 \%$ clay but there is more reduction in charge density that happened in nanocomposite PVC with $10 \%$ clay and there are hetero-charge accumulated charges between the anode and cathode electrodes.

- Adding fumed silica nanoparticles from up to 5\% increases charge density $200 \%$. Also, a progressive of bulk space charge at the electrode field level is observed as the nanofillers concentration increases to 5\%fumed silica but there is high reduction in charge density, reaches to $80 \%$, if fumed silica percentage increased from $5 \%$ up to $10 \%$. With aging under $5 \mathrm{kV}$, charge density at the anode and 
cathode is decreased lightly in PVC with 5\%fumed silica but there is noticed high reduction in charge density that happened in nanocomposite PVC with $10 \%$ fumed silica and there are no hetero-charge accumulated charges between the anode and cathode electrodes.

- Adding $\mathrm{ZnO}$ nanoparticles up to $10 \% \mathrm{ZnO}$ increases charge density $250 \%$ that happened in pure PVC. And so, a progressive of bulk space charge at the electrode field level is observed as the nanofillers concentration increases to $10 \% \mathrm{ZnO}$. With aging under $5 \mathrm{kV}$, charge density at the anode and cathode is increased in PVC with $10 \% \mathrm{ZnO}$ and there are hetero-charge accumulated charges between the anode and cathode electrodes. At aging under $5 \mathrm{kV}$, charge density has been increased at the anode and cathode more than that happened in pure PVC and other studied nanocomposites.

\section{ACKNOWLEDGEMENTS}

The present work was supported by the Science and Technology Development Fund (STDF), Egypt, Grant No: Project ID 505.

\section{REFERENCES}

[1] A. Tzimas, S. M Rowland, L. A. Dissado, M. Fu, and U. H Nilsson, "The effect of dc poling duration on space charge relaxation in virgin XLPE cable peelings" J. Phys. D: Appl. Phys. 43 (2010) 215401 (10pp), 2010.

[2] M. Roy, J.K. Nelson, R.K. MacCrone, L.S. Schadler, C.W. Reed, R. Keefe and W. Zenger, "Polymer Nanocomposite Dielectrics - The Role of the Interface" IEEE Transactions on Dielectrics and Electrical Insulation Vol. 12, No. 4;pp. 629- 643, August 2005.

[3] F. Guastavino, A. Dardano, A. Ratto, E. Torello, P. Tiemblo, M. Hoyos, J.M. Gomez-Elvira, "Electrical Characterization of Polymer-Layered Silicate Nanocomposites" IEEE, Annual Report Conference on Electrical Insulation and Dielectric Phenomena, 2005.

[4] J.Taima, K.Inaoka, T.Maezawa, Y. Tanaka, T. Takada and Y. Murata, "Observation of Space Charge Formation in LDPE/MgO Nano-composite under DC Stress at High Temperature" IEEE, Annual Report Conference on Electrical Insulation and Dielectric Phenomena, 2006.

[5] Xiaobing Dong, Yi Yin*, Zhe Li and Xuguang Li, "Space Charge in Lowdensity Polyethylene /micro-SiO2 composite and Low-density Polyethylene/ nano-SiO, composite with different metal electrode pairs" IEEE, International Conference on Solid Dielectrics, Winchester, UK, July 8-13, 2007.

[6] G. C. Montanari, D. Fabiani, and F. Palmier, "Modification of Electrical Properties and Performance of EVA and PP Insulation through Nanostructure by Organophilic Silicates" IEEE Transactions on Dielectrics and Electrical Insulation Vol. 11, No. 5; October 2004.

[7] Y. Murakami, M. Nemoto, S. Okuzumi, S. Masuda, M. Nagao, N. Hozumi, Y. Sekiguchi and Y. Murata, "DC Conduction and Electrical Breakdown of $\mathrm{MgO} / \mathrm{LDPE}$ Nanocomposite" IEEE Transactions on Dielectrics and Electrical Insulation Vol. 15, No. 1; pp. 33-39, February 2008. 
[8] A Thabet, and J. Fothergill, "Space-Charge Measurement in Composite Dielectrics" IEEE-12th International Middle East Power System Conference "MEPCON 2008" being held in,Aswan, Egypt, March 2008.

[9] T. Takada, Y. Hayase, Y. Tanaka, and T. Okamoto, "Space Charge Trapping in Electrical Potential Well Caused by Permanent and Induced Dipoles for LDPE/MgO Nanocomposite" IEEE Transactions on Dielectrics and Electrical Insulation Vol. 15, No. 1; pp. 152-160, February 2008.

[10] T. Maezawa, J.Taima, Y. Hayase, Y. Tanaka, T. Takada, and Y. Sekiguchi, Y. Murata, "Space Charge Formation in LDPE/MgO Nano-composite under High Electric Field at High Temperature" IEEE, Annual Report Conference on Electrical Insulation and Dielectric Phenomena, 2007.

[11] K. Li, H. Wang, F. Xiang, W. Liu, H. Yang, "Surface functionalized $\mathrm{Ba} 0.6 \mathrm{Sr} 0.4 \mathrm{TiO} 3 / \mathrm{poly}$ (vinylidene fluoride) nanocomposites with significantly enhanced dielectric properties" Applied Physics Letters, Volume: 95 Issue: 20, pp. 202904 - 202904-3, December 2009.

[12] Sh. Okuzumi, Y. Murakami, M. Nagao,Y. Sekiguchi, Ch. Ch. Reddy, and Y. Murata, "DC Breakdown Strength and Conduction Current of MgO/LDPE Composite Influenced by by Filler Size", IEEE, Annual Report Conference on Electrical Insulation Dielectric Phenomena, pp. 722-725, 2008.

[13] N. Vella, A. Toureille, N. Guarrotxena and J. L. Millan, "Thermal Step and TSDC Measurement in PVC" IEEE Transactions on Dielectrics and Electrical Insulation Vol. 7, No.3; pp. 329-333, June 2000.

[14] P. Murugaraj, D. Mainwaring, N. Mora-Huertas, "Dielectric enhancement in polymer-nanoparticle composites through interphase polarizability" Journal of Applied Physics, Volume: 98 Issue: 5, pp. 054304 - 054304-6, June 2005.

[15] J. Zha, Z. Dang, H. Song, Y. Yin, G. Chen, "Dielectric properties and effect of electrical aging on space charge accumulation in polyimide/ $\mathrm{TiO} 2$ nanocomposite films" Journal of Applied Physics, Volume: 108 Issue: 9, pp. 094113 - 094113-6, November 2010.

[16] X. Huang, P. Jiang, Y. Yin, "Nanoparticle surface modification induced space charge suppression in linear low density polyethylene" Applied Physics Letters, Volume: 95 Issue: 24, pp. 242905 - 242905-3, December 2009.

[17] L. Bois, F.Chassagneux, S.Parola, and F.Bessueille. "Growth of ordered silver nanoparticles in silica film mesostructured with a triblock copolymer PEO-PPOPEO” Journal of Solid State Chemistry Vol. 182, pp. 1700-1707, 2009. 


\section{قياسات معملية للشحن الفراغى داخل رقائق فيلمية جديدة من مركبات النانو للبولفينيل}

\section{كلورايد}

تتكيل الثحن الفراغى في رقائق فيلمية من مركبات نانومترية تحت اجهاد التيار المستمر في درجات الحرارة المختلفة تتم باستخدام نظام نابض الكهربائية الصوتية (PEA). مركبات النانومترية المصنوعة من البولي فينيل

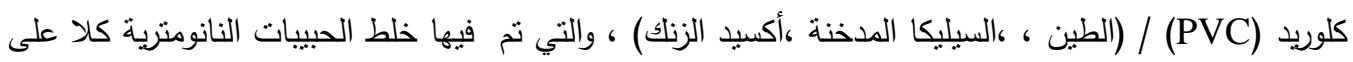

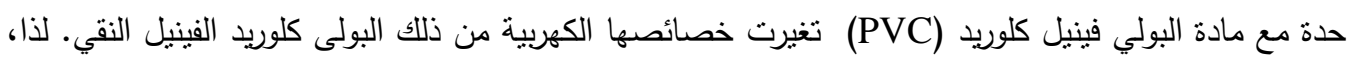

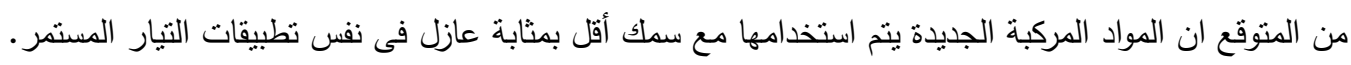

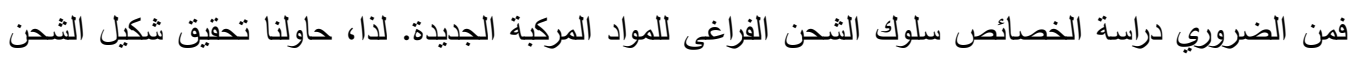

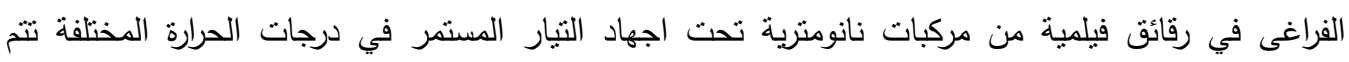

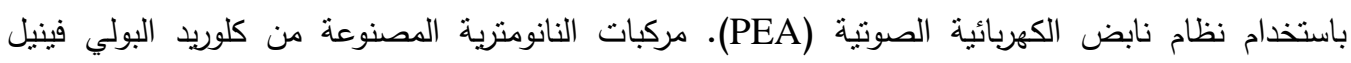

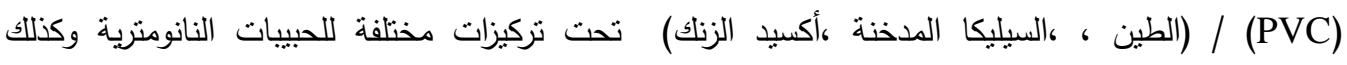

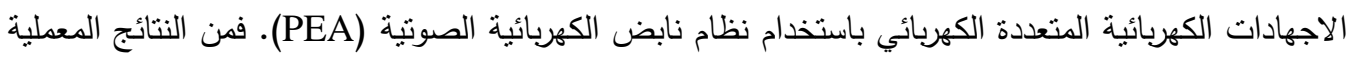

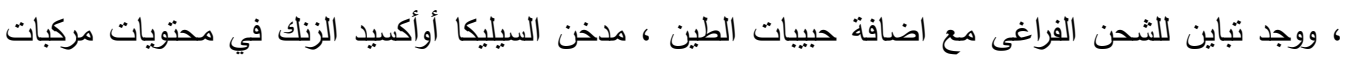

